\title{
Article \\ Quality of Life with Respect to Physical Activity Level in the Unemployed
}

\author{
Daniel Puciato ${ }^{1, *(\mathbb{O})}$, Piotr Oleśniewicz ${ }^{2}$ and Michał Rozpara ${ }^{3}$ \\ 1 Faculty of Physical Education and Physiotherapy, Opole University of Technology, ul. Prószkowska 76, \\ 45-758 Opole, Poland \\ 2 Faculty of Physical Education, University School of Physical Education in Wrocław, Paderewskiego 35 Street, \\ 51-612 Wrocław, Poland; piotr.olesniewicz@awf.wroc.pl \\ 3 Institute of Sport Sciences, The Jerzy Kukuczka Academy of Physical Education, ul. Mikołowska 72A, \\ 40-065 Katowice, Poland; m.rozpara@awf.katowice.pl \\ * Correspondence: d.puciato@po.edu.pl; Tel.: +48-77-44-98-285
}

Received: 6 April 2020; Accepted: 18 May 2020; Published: 21 May 2020

check for updates

\begin{abstract}
Sustainable development is related to the quality of life of individuals and societies. The unemployed have limited opportunities for sustainable individual development. Their life quality conditions remain unclear. The study aim was to assess the relationship between life quality and physical activity level of the unemployed. The research was performed in 2014 and 2015 in Wrocław, Poland, among 403 unemployed persons. The participants' quality of life was evaluated with the World Health Organization Quality of Life questionnaire. Physical activity was assessed with the International Physical Activity Questionnaire. Most respondents evaluated their general life quality as $\leq 3$ points in the scale of $1-5$. The assessments were highest in the social and psychological domains and lowest in the physical and environmental domains. Significant relationships were observed between general life quality and physical activity level. Subjects with the minimum physical activity level recommended by WHO presented higher life quality assessments in the psychological and social domains. Unemployed people with physical activity levels optimal for health benefit evaluated their life quality in the psychological domain worse than people with physical activity below WHO recommendations. Comprehensive health programs should be addressed to the unemployed, including systematic physical activities as health training, which would improve their life quality and promote sustainable individual development.
\end{abstract}

Keywords: quality of life; physical activity; the unemployed; urban agglomeration

\section{Introduction}

The concept of sustainable development, alongside economic and environmental issues, involves social systems, which determine the strong and mutual relations of this paradigm of development with the quality of life category. These relationships are, moreover, based on the very definition of sustainable development, as both the Brundtland Commission Report [1] and the Rio Declaration [2] indicate that it is a development that ensures that the needs and quality of life of modern society are met without compromising the opportunity to meet the needs of future generations. In accordance with the WHO definition [3], the term 'quality of life' should also be understood holistically as an individual's perception of their own life situation in the context of the cultural conditions and system of values in which they live and in relation to the tasks, expectations, and standards set by the environmental conditions. According to Borys [4], it can be considered that the implementation of sustainable development principles is synonymous with the pursuit of a high quality of life, and the sub-indicators describing sustainable development can also be applied to determine quality of life. 
Moreover, Greenwood and Holt [5] point to four important reasons for highlighting the links between sustainable development and quality of life. Firstly, economic development is a much broader category than economic growth. Secondly, raising the standard of living is associated with both quality of life and income. Thirdly, improving living standards must be environmentally and socially sustainable. Fourthly, the improvement in living standards should be widespread and affect as many people as possible. Strong interdependencies between sustainable development and quality of life have been demonstrated by Cesar Cantu-Martinez [6], Fritz and Koch [7], and Pissourios [8].

The literature emphasizes the links between sustainable development policy and human health. One should consider sustainable production and consumption of goods as crucial in this context with regard to the economic area, environmental and health safety within the environmental area, and homeland security with reference to the social area [9]. Scientific research results also indicate that regular physical activity can be an important tool for maintaining health, which has a positive impact on the well-being, cognitive processes, and level of optimism [10], as well as on the function of the motor, circulatory, respiratory, digestive, immune, and nervous systems [11,12]. Among other factors, physical activity can support the educational process, play an important role in social integration, reflected in tolerance and respect for others, and contribute to the sustainable development of the individual. The objective of sustainable individual development is to promote long, healthy, and autonomous life, in harmony with the natural and social environment and economic needs [13]. The issues of the links between sustainable development, quality of life, and physical activity were dealt with by Bestard and Machado [14], as well as by Zou et al. [15].

Unemployed people are a group with particularly limited opportunities for sustainable individual development. Unemployment, especially long-term, is associated with a number of negative economic, social, and psychological consequences for the unemployed and their families. The reduction in household income restricts the ability to meet individual and group needs. Lack of work results in the loss of professional qualifications or skills, which makes return to work difficult or even impossible [16]. As a consequence, the decline of social contacts continues, family conflicts arise, there occurs a sense of social exclusion and loss of the former social position [17]. The highest costs are faced by the unemployed themselves, who experience emotional disorders, increased susceptibility to disease, and reduced quality of life [18].

The results of previous studies indicate a low level of quality of life [19] and physical activity [20] in the unemployed. The relationship between the quality of life and physical activity in the unemployed has not yet been fully explained. Szemik et al. [21] reported that while the low quality of life of professionally active people was correlated with a low level of physical activity, low level of job satisfaction, low average income, and low level of education, in the case of the unemployed similar relationships were observed only with respect to financial situation and satisfaction with personal relationships. Neither did Schuring et al. [22] notice significant relationships between life quality and physical activity; therefore, they proposed to combine physical activity programs with regular vocational counseling for the unemployed. According to the authors, only such a comprehensive solution can have a positive impact on health, quality of life, self-esteem, and effectiveness of job search. In turn, a negative influence of low physical activity on health and quality of life in the unemployed was shown by Dedele et al. [23].

Hence, it is still unknown whether physical activity significantly modifies the quality of life of the unemployed, or perhaps other conditions are more important. Additionally, the research to date has not considered physical activity as assessed by the World Health Organization (WHO) as a potential determinant of the quality of life in unemployed people. The criteria used in the present study to assess the respondents' level of physical activity seem particularly innovative as they resulted in dividing the subjects into the following groups: individuals not physically active enough for health benefit (not meeting WHO recommendations), people physically active enough at a minimum level (meeting core WHO recommendations), and those physically active enough at an optimal level (meeting additional 
WHO recommendations). The outlined issues constitute a specific research gap, whose bridging is among the most important objectives of the paper.

The aim of the study was to assess relationships between the quality of life and the level of physical activity in unemployed people from Wrocław, Poland. The purpose was specified in two research questions:

1. How do the unemployed from Wrocław assess their quality of life and physical activity level?

2. Are there any relationships between quality of life and physical activity in the unemployed citizens of Wrocław?

The following hypotheses were adopted for the presented research questions:

1. The investigated unemployed from Wrocław assess their quality of life and physical activity level as low.

2. There are positive relationships between the quality of life and the level of physical activity of the unemployed.

\section{Materials and Methods}

The research was performed in 2014 and 2015 in Wrocław, Poland. Wrocław is a city located in south-western Poland, which was inhabited by 634,487 people in 2015 . Women constituted $53.4 \%$ and men $46.6 \%$ of the city population. In 2015 , out of the 248,992 people who worked, the highest percentage were employed in industry (15.0\%), trade and repair of motor vehicles $(13.6 \%)$, education $(12.0 \%)$, administration and support activities $(8.8 \%)$, healthcare and social welfare $(7.7 \%)$, professional, scientific, and technical activities (7.3\%), financial and insurance activities (6.9\%), information and communication $(6.7 \%)$, and public administration, national defence, and social security $(6.6 \%)$. The unemployment rate was low and amounted to $4.1 \%$ in 2014 and $3.3 \%$ in 2015 [24].

The paper is based on the results of a survey carried out in a group of 403 unemployed people selected from among 4332 individuals (2276 women and 2056 men) who participated in research on socioeconomic determinants of the quality of life and physical activity of people of working age residing in Wrocław. The research project had been given a positive opinion by the Commission of Bioethics of the University School of Physical Education in Wrocław.

The sample size was estimated based on the following formula [25]:

$$
\mathrm{n}=\frac{\mathrm{N}}{1+\frac{\mathrm{e}^{2}(\mathrm{~N}-1)}{\mathrm{u}_{\alpha}^{2} \mathrm{pq}}}
$$

where: N-the number of Wrocław inhabitants as of 31 December $2013(\mathrm{~N}=632,067) ; \mathrm{p}$ 一the fraction of Wrocław population of working age as of 31 December $2013(\mathrm{p}=0.63)$; $q$-constant equal $1-p(q=$ $0.37) ; \mathrm{e}-$ the assumed error of $\mathrm{p}$ fraction estimation $(\mathrm{e}=1.5) ; \mathrm{u}_{\alpha}$ - the value of standardized normal distribution $\mathrm{N}(0,1)$ for the confidence coefficient $1-\alpha\left(\mathrm{z}_{\alpha}=1.96\right.$ for $\left.\alpha=0.05\right)$.

The minimum sample size for the survey was estimated at 4122 individuals, so the number of questionnaires collected $(\mathrm{N}=4332)$ was higher than required.

The selection of the research sample was multistage and had a mixed character (random and nonprobability sampling). In the first step of the selection, by using a random number table, 10 housing estates in Wrocław were drawn. In the second step, with the same random mechanism, 3 streets were selected from each of the 10 housing estates. In the last step, from among passers-by encountered in the selected streets, every fourth person was asked to participate in the survey. The following inclusion criteria were assumed in the study: holding the status of an unemployed person, period of unemployment: at least 1 year, address of residence: in one of the selected streets, working age (18-64 years). The exclusion criteria involved pregnancy and chronic diseases, e.g., cancer, diabetes, arterial hypertension, osteoarthritis, osteoporosis. All respondents were informed about the purpose 
and course of the survey and about their voluntary participation. They were asked to provide their informed consent to participate.

From among all the participants, 403 unemployed people ( 246 women and 157 men) were included in the article. Among the unemployed respondents from Wrocław, women (61.0\%) prevailed over men $(39.0 \%)$. Almost every fourth person $(23.6 \%)$ was aged $18-24$ years, $21.1 \%$ were $25-34$ years old, $3.7 \%$ were $35-44$ years old, $14.4 \%$ were $45-54$ years old, and $37.2 \%$ were aged $55-64$ years. Among the subjects, $71.2 \%$ had basic vocational or lower education, $23.3 \%$ had secondary education, and $5.5 \%$ had higher education. Unmarried persons constituted $47.1 \%$ of the subjects, while married people accounted for $52.9 \%$ (Table 1).

Table 1. Sociodemographic characteristics of unemployed Wrocław inhabitants $(\mathrm{N}=403)$.

\begin{tabular}{lcc}
\hline \multicolumn{1}{c}{ Variable } & $\mathbf{n}$ & $\mathbf{\%}$ \\
\hline Female & Gender & \\
Male & 246 & 61.0 \\
& 157 & 39.0 \\
18-24 years & Age & \\
25-34 years & 95 & 23.6 \\
35-44 years & 85 & 21.1 \\
45-54 years & 15 & 3.7 \\
55-64 years & 150 & 14.4 \\
\hline & Education & 37.2 \\
Primary & 287 & 71.2 \\
Secondary & 94 & 23.3 \\
University & 22 & 5.5 \\
\hline & Marital status \\
Single & 190 & 47.1 \\
Married & 213 & 52.9 \\
\hline
\end{tabular}

The method of a diagnostic survey with the questionnaire technique was applied. Physical activity was assessed with the International Physical Activity Questionnaire, Short Form (IPAQ-SF) [26]. It is currently among the most popular standardized worldwide research tools used to measure physical activity. Despite a higher measurement error compared with e.g., accelerometry, the high cost-effectiveness and practicality of IPAQ-SF makes it one of the better tools for measuring physical activity in population studies [27]. Moreover, the measurement error of the IPAQ-SF is of a systematic character, which means that it is similar for each subject. As a result, it does not significantly affect the results of research evaluating relationships between traits, which is the case in this study. The questionnaire consists of 6 questions on the frequency and duration of vigorous-, moderate-, and low-intensity physical activity and 1 question on the time spent sitting in the week preceding the survey. On the basis of data collected with IPAQ-SF, the level of habitual physical activity was determined with the consideration of WHO recommendations. The following categories of respondents were distinguished:

1. People physically active at a minimum level for health benefit: those who met only the basic WHO recommendations for a weekly dose of health-enhancing physical activity, i.e., $75 \mathrm{~min} /$ week of vigorous-intensity physical activity or $150 \mathrm{~min} /$ week of moderate-intensity physical activity or an equivalent physical activity volume of the two intensity levels.

2. People physically active at an optimal level for health benefit: those who met, in addition to the basic ones, also additional WHO recommendations for a weekly dose of health-enhancing physical activity, i.e., $150 \mathrm{~min} /$ week of vigorous-intensity physical activity or $300 \mathrm{~min} /$ week of moderate-intensity physical activity or an equivalent physical activity volume of the two intensity levels. 
3. People physically active below the minimum level for health benefit: those who met neither basic nor additional WHO recommendations for a weekly dose of health-enhancing physical activity [28].

The participants' quality of life was evaluated with the World Health Organization Quality of Life (WHOQOL-BREF) scale [29]. The questionnaire consists of 26 questions and allows an assessment of quality of life in general (overall quality of life), as well as in four domains: the physical domain, the psychological domain, the social domain, and the environmental domain. The answers to the particular survey questions are presented on an interval (point) scale. For the overall quality of life assessment, the score range is $1-5$ points ( 1 being the worst and 5 being the best score), whereas with respect to the individual quality of life domains, the score range is 4-20 points (with 4 as the worst and 20 as the best score) [25]. The quality of life level (overall and in particular domains) is also expressed on an ordinal scale. The median value (Me) was used as a division point in the classification for those variables where results equal to or lower than Me meant an average or lower level of life quality and results higher than Me indicated an above-average life quality level.

Arithmetic means $(\bar{x})$ and standard deviations (s) were determined for quality of life and physical activity level variables. The numbers ( $\mathrm{n}$ ) and percentages $(\%)$ of respondents in the analyzed variable categories were also calculated. Binary logistic regression served to assess the relationships between quality of life and physical activity level. The statistical significance level of $\alpha=0.05$ was assumed. The calculations were performed with the IBM SPSS Statistics 26 software (IBM Corporation, Armonk, NY, USA).

\section{Results}

The average assessment of the overall quality of life of the unemployed Wrocław inhabitants equalled $3.1 \pm 0.9$ points. In the surveyed population, $67 \%$ evaluated their overall quality of life as average or lower than average, and $33 \%$ as higher than average. The respondents rated their quality of life best in the social domain (14.2 \pm 2.8 points) and in the psychological domain (13.0 \pm 2.3 points), and worst in the physical domain (12.0 \pm 1.7 points) and in the environmental domain (12.0 \pm 2.3 points). In the examined group of the unemployed, the greatest percentage of higher than average quality of life ratings was recorded in the following domains: physical (46.2\%), psychological $(45.2 \%)$, and environmental (42.7\%), and the lowest percentage of these scores was observed in the social domain $(36.7 \%)$. The average weekly volume of total physical activity was $483.2 \pm 253.6 \mathrm{~min}$. Low-intensity efforts had the greatest share in the total of physical activity ( $264.5 \pm 134.7 \mathrm{~min} /$ week), with the smallest share made up of vigorous-intensity efforts ( $155.5 \pm 85.6 \mathrm{~min} /$ week $)$. Moderate-intensity physical activity was implemented for $179.0 \pm 113.2 \mathrm{~min} /$ week on average. Most participants $(71.5 \%)$ met the weekly physical activity standards recommended by WHO. The level of physical activity optimal from the point of view of positive impact on health was declared by $40.5 \%$ of the respondents, and $31.0 \%$ indicated the minimum physical activity level. A level of physical activity lower than WHO recommendations was recorded among $28.5 \%$ of the unemployed inhabitants of Wrocław (Tables 2 and 3).

Table 4 presents the results of the logistic regression analysis showing relationships between the quality of life and physical activity in unemployed Wrocław residents. The chances of an above-average assessment of the overall quality of life were more than twice as high in subjects physically active at the optimal level for health benefit (OR $=2.04$; CI: 1.22-3.42) than in those with insufficient levels of physical activity according to WHO recommendations. The level of physical activity of the unemployed was also related to their quality of life in the psychological and social domains. In subjects who were physically active at the minimum level for health benefit, there was a $75 \%$ higher chance of an above-average evaluation of the quality of life in the psychological domain compared with physically inactive respondents. The lower bound of the odds ratio confidence interval was 1.05, while the upper bound equalled 2.92. The conditional probability of an above-average assessment of life quality in the psychological domain among unemployed Wrocław inhabitants with optimal physical activity for health benefit was $52 \%$ lower than in those with insufficient levels of physical activity (OR $=0.48$; CI: 
0.29-0.79). The chances of an above-average assessment of the quality of life in the social domain in people meeting the minimum criteria for health-enhancing physical activity were almost twice as high as in those who did not meet these criteria $(\mathrm{OR}=1.98$; CI: 1.18-3.34).

Table 2. Descriptive statistics of the quality of life and physical activity among unemployed Wrocław inhabitants $(\mathrm{N}=403)$.

\begin{tabular}{lcc}
\hline \multicolumn{1}{c}{ Variable } & $\overline{\mathbf{x}}$ & s \\
\hline & Quality of life & \\
Overall [points] & 3.1 & 0.9 \\
Physical domain [points] & 12.0 & 1.7 \\
Psychological domain [points] & 13.0 & 2.3 \\
Social domain [points] & 14.2 & 2.8 \\
Environmental domain [points] & 12.0 & 2.3 \\
\hline \multicolumn{4}{c}{ Physical activity } \\
Vigorous-intensity [min/week] & 155.5 & \\
Moderate-intensity [min/week] & 179.0 & 85.6 \\
Low-intensity [min/week] & 264.5 & 113.2 \\
Total [min/week] & 483.2 & 134.7 \\
\hline
\end{tabular}

Notes: $\bar{x}$ : mean; s: standard deviation.

Table 3. Numbers and percentages of unemployed Wrocław inhabitants with variable levels of quality of life and physical activity $(\mathrm{N}=403)$.

\begin{tabular}{|c|c|c|}
\hline Variable & $\mathbf{n}$ & $\%$ \\
\hline \multicolumn{3}{|c|}{ General quality of life } \\
\hline Average or below ( $\leq 3$ points) & 270 & 67.0 \\
\hline Above average ( $>3$ points) & 133 & 33.0 \\
\hline \multicolumn{3}{|c|}{ Physical domain quality of life } \\
\hline Average or below ( $\leq 12$ points) & 217 & 53.8 \\
\hline Above average ( $>12$ points) & 186 & 46.2 \\
\hline \multicolumn{3}{|c|}{ Psychological domain quality of life } \\
\hline Average or below ( $\leq 13$ points) & 221 & 54.8 \\
\hline Above average ( $>13$ points) & 182 & 45.2 \\
\hline \multicolumn{3}{|c|}{ Social domain quality of life } \\
\hline Average or below ( $\leq 15$ points) & 255 & 63.3 \\
\hline Above average ( $>15$ points) & 148 & 36.7 \\
\hline \multicolumn{3}{|c|}{ Environmental domain quality of life } \\
\hline Average or below ( $\leq 12$ points) & 231 & 57.3 \\
\hline Above average ( $>12$ points) & 172 & 42.7 \\
\hline \multicolumn{3}{|c|}{ Health-enhancing physical activity level by WHO } \\
\hline Minimal physical activity level & 125 & 31.0 \\
\hline Optimal physical activity level & 163 & 40.5 \\
\hline Below minimal physical activity level & 115 & 28.5 \\
\hline
\end{tabular}


Table 4. Relationships between quality of life and physical activity in the light of logistic regression $(\mathrm{N}=403)$.

\begin{tabular}{|c|c|c|c|c|c|c|c|}
\hline \multirow{2}{*}{ Variable } & \multirow{2}{*}{$\beta$} & \multirow{2}{*}{ SE } & \multirow{2}{*}{ Wald $\chi^{2}$} & \multirow{2}{*}{$p$} & \multirow{2}{*}{ OR } & \multicolumn{2}{|c|}{ CI } \\
\hline & & & & & & $-95 \%$ & $95 \%$ \\
\hline \multicolumn{8}{|c|}{ General quality of life } \\
\hline Intercept & -1.00 & 0.21 & 22.50 & $<0.001$ & & & \\
\hline $\begin{array}{l}\text { Minimal vs. below } \\
\text { minimal PAL }\end{array}$ & -0.07 & 0.29 & 0.06 & 0.811 & 0.93 & 0.52 & 1.66 \\
\hline $\begin{array}{l}\text { Optimal vs. below } \\
\text { minimal PAL }\end{array}$ & 0.71 & 0.26 & 7.34 & 0.007 & 2.04 & 1.22 & 3.42 \\
\hline \multicolumn{8}{|c|}{ Physical domain quality of life } \\
\hline Intercept & -0.26 & 0.19 & 1.95 & 0.163 & & & \\
\hline $\begin{array}{l}\text { Minimal vs. below } \\
\text { minimal PAL }\end{array}$ & 0.31 & 0.26 & 1.43 & 0.232 & 1.36 & 0.82 & 2.27 \\
\hline $\begin{array}{l}\text { Optimal vs. below } \\
\text { minimal PAL }\end{array}$ & 0.03 & 0.25 & 0.01 & 0.909 & 1.03 & 0.64 & 1.66 \\
\hline \multicolumn{8}{|c|}{ Psychological domain quality of life } \\
\hline Intercept & -0.09 & 0.19 & 0.22 & 0.641 & & & \\
\hline $\begin{array}{l}\text { Minimal vs. below } \\
\text { minimal PAL }\end{array}$ & 0.56 & 0.26 & 4.58 & 0.033 & 1.75 & 1.05 & 2.92 \\
\hline $\begin{array}{l}\text { Optimal vs. below } \\
\text { minimal PAL }\end{array}$ & -0.73 & 0.25 & 8.37 & 0.004 & 0.48 & 0.29 & 0.79 \\
\hline \multicolumn{8}{|c|}{ Social domain quality of life } \\
\hline Intercept & -0.67 & 0.20 & 11.47 & 0.001 & & & \\
\hline $\begin{array}{l}\text { Minimal vs. below } \\
\text { minimal PAL }\end{array}$ & 0.68 & 0.27 & 6.59 & 0.010 & 1.98 & 1.18 & 3.34 \\
\hline $\begin{array}{l}\text { Optimal vs. below } \\
\text { minimal PAL }\end{array}$ & -0.27 & 0.26 & 1.03 & 0.311 & 0.77 & 0.46 & 1.28 \\
\hline \multicolumn{8}{|c|}{ Environmental domain quality of life } \\
\hline Intercept & -0.16 & 0.19 & 0.70 & 0.402 & & & \\
\hline $\begin{array}{l}\text { Minimal vs. below } \\
\text { minimal PAL }\end{array}$ & -0.25 & 0.26 & 0.90 & 0.342 & 0.78 & 0.47 & 1.30 \\
\hline $\begin{array}{l}\text { Optimal vs. below } \\
\text { minimal PAL }\end{array}$ & -0.15 & 0.25 & 0.39 & 0.534 & 0.86 & 0.53 & 1.39 \\
\hline
\end{tabular}

\section{Discussion}

The analysis of the conducted research results showed that the unemployed from Wrocław most often assessed their quality of life as low. This probably results from the fact that unemployment brings many negative health consequences, and long-term stress associated with lack of work often leads to a decrease in life quality and mental condition. This observation is confirmed by the results of previous studies $[19,30]$. Additionally, higher average values of quality of life indicators in employed people compared with the unemployed have been documented. In a study by Soltysik et al. [31], quality of life was rated at 76.2 points on average (in a scale of $0-100$ ) by white-collar workers, at 72.2 points by manual workers, and at 71.2 points by the unemployed $(p<0.05)$. Moreover, Yang et al. [32] revealed that quality of life assessment deteriorated with the duration of the respondents' unemployment period. People who were unemployed for 1-2 months evaluated their quality of life as 76.2 points on average in the physical domain and as 65.1 points in the psychological domain, while the respective results among those unemployed for 12 months or longer equalled 66.9 points and 60.0 points $(p<0.01)$. In turn, a lower quality of life in professionally active people as compared with the unemployed was noticed by Czekirda et al. [33]. Moreover, Carlier et al. [34] indicated that the quality of life assessment of people who had been unemployed for a certain period and then started to work for a living was 
systematically improved. This is an important practical observation, as it confirms the possibility to change the assessment of life quality among people whose life situation has changed and underlines the important role of active methods of dealing with unemployment in the process of finding jobs for the unemployed and, consequently, improving their quality of life.

The unemployed Wrocław residents evaluated their life quality best in the social and psychological domains, and worst in the physical and environmental domains. In turn, the majority of previous research emphasized the negative impact of unemployment on the quality of life in the psychological domain, in both younger and older groups [35]. This, however, referred to long-term unemployment [36], and the duration of the participants' unemployment was not analyzed in the discussed study. An interesting observation was reported by Szemik et al. [21], who not only analyzed the difference in quality of life assessment between the employed and the unemployed, but also took into consideration the level of work satisfaction. It turned out that the respondents dissatisfied with their own work were characterized by a lower health-related quality of life in all domains than the unemployed.

The relatively high level of physical activity of the examined unemployed people seems surprising, as most of them fulfilled the WHO recommendations. However, the study did not compare the physical activity of the unemployed and the employed. The results of previous studies clearly indicate a higher level of physical activity in professionally active people, especially in the case of moderateand vigorous-intensity physical effort [36,37]. This cannot be said about low-intensity physical effort: according to Dedele et al. [23], unemployed people were twice as likely to walk and cycle in winter and almost three times in summer compared with the employed. Among the participants from Wrocław, the structure of weekly physical activity was dominated by low-intensity physical efforts, which constituted more than half of total physical activity.

The chances of an above-average assessment of the overall quality of life were higher in subjects with physical activity at the optimal level for health benefit according to WHO than in those with physical activity levels lower than recommended by WHO. The few studies on the relationships between the quality of life and physical activity in the unemployed have so far been inconclusive. Positive links between quality of life and physical activity were observed by Dedele et al. [23]; in turn, Szemik et al. [21] and Schuring et al. [22] reported no significant correlations between these categories. Previous studies have, however, quite often revealed a positive impact of physical activity on the overall quality of life in adults, regardless of their professional status [38-40].

The physical activity level of the unemployed Wrocław inhabitants also positively correlated with their quality of life in the social domain. This is important because some of the respondents may have already experienced the first symptoms of ageing, such as a decrease in physical fitness, or health problems in the sexual area. This can have a negative impact on human functioning in society, interpersonal relations, or the possibility of professional work. Physical activity can then have preventive and therapeutic roles, contributing to a more optimistic perception of one's professional prospects, intensification of social contacts, or improvement of sexual function [41]. Similarly, Guimarães and Baptista [42] recorded a higher quality of life in this domain among physically active people compared with the unemployed.

The results of the present study illustrating the relationships between the quality of life in the psychological domain and physical activity were not conclusive. On the one hand, the chances of an above-average quality of life assessment were higher in people with minimal physical activity for health benefit than in those with insufficient physical activity in the light of WHO recommendations. On the other hand, individuals who were not physically active enough were more likely to present an above-average quality of life assessment compared with those with physical activity at the optimal level to obtain health benefit. This can be considered an artefact, as the results of previous studies were mostly different $[43,44]$. However, this may also indicate that moderate physical activity is sufficient in terms of modeling the quality of life in the psychological domain in the unemployed. The literature has documented the positive and sometimes crucial role of moderate physical activity in the reduction of 
stress in adults. Such forms of physical activity as walking, running, swimming, cycling, body shaping exercises including relaxation and stretching, housework, or gardening are especially preferred [45]. Moreover, it should be emphasized that Herman et al. [46] also reported higher quality of life in the psychological domain in women who were less physically active than in more physically active subjects. In turn, in the studies by Schuring et al. [22], the assessment of health-related quality of life in the psychological domain did not differ significantly between groups with high and low levels of physical activity.

The presented paper has its strengths and limitations. The former certainly include the examined study group, as the relationships between health-related quality of life and physical activity of the unemployed has rarely been addressed before. Neither has the issue been investigated with the consideration of the particular quality of life domains (physical, psychological, social, and environmental) or levels of physical activity for health benefit (minimal or optimal). This represents an added value to scientific resources. The results of previous studies indicated insignificant or weak correlations between the quality of life and the level of physical activity of the unemployed. Moreover, the present research has shown that the significance, strength, and directions of the relationships vary depending on the quality of life domain and the extent to which health-related recommendations for physical activity are met. Previous studies did not consider these aspects of the undertaken investigation at all. The main limitation of the study is its spatial scope, restricted to one city. This scope should be extended to the whole of Poland, and even to other Central European countries in future studies. Additionally, the results of the research on the relationships between quality of life and physical activity are not homogenous. This may be a specific artefact due to the restricted sample size; it may also be related to the existence of other predictors of life quality in the unemployed equally significant as physical activity, such as health status, economic situation, interpersonal relations, and others. Further studies should therefore increase the number of respondents and take into account other variables that potentially modify quality of life assessment in unemployed people.

\section{Conclusions}

Among the study participants, significant relationships were observed between life quality and physical activity level. The subjects who met the WHO recommendations on minimum health-enhancing level of physical activity were characterized by higher average assessments of life quality in the psychological and social domains. Those with physical activity levels optimal for health benefit evaluated their general life quality better and their life quality in the psychological domain worse than people with insufficient physical activity levels.

As a result of the research carried out, it is recommended that measures be taken to increase physical activity among the unemployed; this may contribute to their quality of life improvement and sustainable development. Particularly noteworthy in this case are comprehensive professional reintegration and health promotion programs, including, among others, activities aimed at maintaining and improving health through physical and mental training, as well as raising individual professional competences.

Author Contributions: Study Design-D.P.; Data Collection-D.P.; Statistical Analysis-M.R.; Data Interpretation-D.P., P.O., M.R.; Manuscript Preparation-D.P., P.O., M.R.; Literature Search-P.O. All authors have read and agreed to the published version of the manuscript.

Funding: University School of Physical Education in Wrocław, Opole University of Technology.

Conflicts of Interest: The authors declare no conflict of interest.

\section{References}

1. Report of the World Commission on Environment and Development: Our Common Future; Oxford University Press: Oxford, UK, 1987; p. 300.

2. The Rio Declaration on Environment and Development; United Nations Conference on Environment and Development: Rio de Janeiro, Brazil, 1992; p. 5. 
3. Measuring Quality of Life. Division of Mental Health and Prevention of Substance Abuse; WHO: Geneva, Switzerland, 1997; p. 3.

4. Borys, T. Sustainable development. How to recognize integrated order. Probl. Ekorozw. 2011, 6, 75-81.

5. Greenwood, D.; Holt, R. Local Economic Development in the 21st Century: Quality of Life and Sustainability; M.E. Sharpe: Armonk, NY, USA, 2010; p. 215.

6. Cesar Cantu-Martinez, P. Quality of life and sustainability: A new citizenship. Ambiente Desarro. 2015, 19, 9-21.

7. Fritz, M.; Koch, M. Potentials for prosperity without growth: Ecological sustainability, social inclusion and the quality of life in 38 countries. Ecol. Econom. 2014, 108, 191-199. [CrossRef]

8. Pissourios, I. An interdisciplinary study on indicators: A comparative review of quality-of-life, macroeconomic, environmental, welfare and sustainability indicators. Ecol. Indic. 2013, 34, 420-427. [CrossRef]

9. Borys, T. Wpływ polityki zrównoważonego rozwoju na zdrowie człowieka. Ekonatura 2014, 5, 25-30.

10. Heiestad, H.; Rustaden, A.; Bø, K.; Haakstad, L. Effect of regular resistance training on motivation, self-perceived health, and quality of life in previously inactive overweight women: A randomized, controlled trial. BioMed Res. Int. 2016, 2016, 3815976. [CrossRef]

11. Aparicio-Sarmiento, A.; Rodríguez-Ferrán, O.; Martínez-Romero, M.; Cejudo, A.; Santonja, F.; Sainz de Baranda, P. Back pain and knowledge of back care related to physical activity in 12 to 17 year old adolescents from the Region of Murcia (Spain): ISQUIOS Programme. Sustainability 2019, 11, 5249. [CrossRef]

12. Mynarski, W.; Królikowska, B.; Rozpara, M.; Nawrocka, A.; Puciato, D. The caloric cost of practicing martial arts on the background of health recommendation. Arch. Budo 2013, 2, 125-132.

13. Mariéthoz, E.; Bakonyi-Moeschler, M. Role of physical activity in health promotion and (individual) sustainable development. Int. J. Sustain. Dev. World 2003, 10, 221-224. [CrossRef]

14. Bestard, Y.; Machado, C. Physical activity and environmental education for the quality of life: More to sustainability? Remea-Rev. Eletron. Mestr. Educ. Ambient. 2015, 3, $29-37$.

15. Zou, H.; Kayani, S.; Wang, J.; Imran, I.; Sánchez, M.; Jesús, L.; Qurban, H. A study on the relationship between urban residents' perception of recreational sports and their participation in recreational sports: Based on gender differences. Sustainability 2019, 11, 5466. [CrossRef]

16. Zhang, C.; De Figueiredo, J. Are recessions good for government hires? The effect of unemployment on public sector human capital. Econ. Lett. 2018, 170,1-5. [CrossRef]

17. Vossemer, J.; Gebel, M.; Taht, K.; Unt, M.; Hogberg, B.; Strandh, M. The effects of unemployment and insecure jobs on well-being and health: The moderating role of labor market policies. Soc. Indic. Res. 2018, 138, 1229-1257. [CrossRef]

18. Krug, G.; Eberl, A. What explains the negative effect of unemployment on health? An analysis accounting for reverse causality. Res. Soc. Stratif. Mobil. 2018, 55, 25-39. [CrossRef]

19. Worach-Kardas, H.; Kostrzewski, S. Quality of life and health state of long-term unemployed in older production age. Appl. Res. Qual. Life 2014, 9, 335-353. [CrossRef]

20. Biernat, E.; Piątkowska, M. Leisure time physical activity among employed and unemployed women in Poland. Hong Kong J. Occup. Ther. 2017, 29, e47-e54. [CrossRef]

21. Szemik, S.; Kowalska, M.; Kulik, H. Relation between occupational activity, health and quality of life among young inhabitants of Silesien voivodeship. Prz. Epidemiol. 2018, 72, 87-98.

22. Schuring, M.; Burdorf, A.; Voorham, A.; Der Weduwe, K.; Mackenbach, J. Effectiveness of a health promotion programme for long-term unemployed subjects with health problems: A randomised controlled trial. J. Epidemiol. Commun. Health 2009, 63, 893-899. [CrossRef]

23. Dedele, A.; Miškinyte, A.; Andrušaityte, S.; Nemaniūte-Gužiene, J. Seasonality of physical activity and its association with socioeconomic and health factors among urban-dwelling adults of Kaunas, Lithuania. BMC Public Health 2019, 19, 1067. [CrossRef]

24. Statistical Yearbook of Wroclaw. Available online: http://www.stat.gov.pl (accessed on 10 October 2019).

25. Brzeziński, J. Methodology of Psychological Research; PWN: Warsaw, Poland, 2011; p. 684.

26. International Physical Activity Questionnaire. Available online: http://ipaq.ki.se/ipaq.htm (accessed on 17 October 2014). 
27. Craig, C.; Marshall, A.; Sjostrom, M.; Bauman, A.; Booth, M.; Ainsworth, B.; Pratt, M.; Ekelund, U.; Yngve, A.; Sallis, J.; et al. International physical activity questionnaire: 12-country reliability and validity. Med. Sci. Sport Exerc. 2003, 35, 1381-1395. [CrossRef]

28. World Health Organization. Global Recommendations on Physical Activity for Health; World Health Organization: Geneva, Switzerland, 2010.

29. The World Health Organization Quality of Life (WHOQOL). Available online: http://www.who.int (accessed on 10 October 2014).

30. Mechili, E.; Kalokairinou, A.; Kaitelidou, D.; Galanis, P.; Diomidous, M. Health related quality of life in the unemployed population during the financial crisis. Arch. Hell. Med. 2017, 34, 65-74.

31. Soltysik, B.; Kroc, L.; Piglowska, M.; Guligowska, A.; Smigielski, J.; Kostka, T. An evaluation of the work and life conditions and the quality of life in 60 to 65 year-old white-collar employees, manual workers, and unemployed controls. J. Occup. Environ. Med. 2017, 59, 461-466. [CrossRef] [PubMed]

32. Yang, X.; Yao, L.; Wu, H.; Wang, Y.; Liu, L.; Wang, J.; Wang, L. Quality of life and its related factors in Chinese unemployed people: A population-based cross-sectional study. Int. J. Environ. Res. Public Health 2016, 13, 797. [CrossRef] [PubMed]

33. Czekirda, M.; Chrusciel, P.; Czekirda, N.; Jarosz, M. Psychosocial aspect of quality of life among working and unemployed nurses and midwives. Ann. Agric. Environ. Med. 2017, 24, 472-476. [CrossRef]

34. Carlier, B.; Schuring, M.; Lotters, F.; Bakker, B.; Borgers, N.; Burdorf, A. The influence of re-employment on quality of life and self-rated health, a longitudinal study among unemployed persons in the Netherlands. BMC Public Health 2013, 13, 503. [CrossRef]

35. Hultman, B.; Hemlin, S. Self-rated quality of life among the young unemployed and the young in work in northern Sweden. Work 2008, 30, 461-472.

36. Buchtova, B. Quality of life of long-time unemployed. Ceskoslov. Psychol. 2004, 48, 121-135.

37. Gabrys, L.; Michallik, L.; Thiel, C.; Vogt, L.; Banzer, W. Effects of a structured physical-activity counseling and referral scheme in long-term unemployed individuals: A pilot accelerometer study. Behav. Med. 2013, 39, 44-50. [CrossRef]

38. Herman, K.; Hopman, W.; Vandenkerkhof, E.; Rosenberg, M. Physical activity, body mass index, and health-related quality of life in Canadian adults. Med. Sci. Sport Exerc. 2012, 44, 625-636. [CrossRef]

39. Pucci, G.; Rech, C.; Fermino, R.; Reis, R. Association between physical activity and quality of life in adults. Rev. Saude Publica 2012, 46, 166-179. [CrossRef]

40. Fang, Y.; Huang, C.; Hsu, M. Effectiveness of a physical activity program on weight, physical fitness, occupational stress, job satisfaction and quality of life of overweight employees in high-tech industries: A randomized controlled study. Int. J. Occup. Saf. Ergon. 2019, 25, 621-629. [CrossRef] [PubMed]

41. Bach, L.; Mortimer, J.; VandeWeerd, C.; Corvin, J. The association of physical and mental health with sexual activity in older adults in a retirement community. J. Sex. Med. 2013, 10, 2671-2678. [CrossRef] [PubMed]

42. Guimarães, A.; Baptista, F. Influence of habitual physical activity on the symptoms of climacterium/menopause and the quality of life of middle-aged women. Int. J. Womens Health 2011, 3, 319-328. [CrossRef] [PubMed]

43. Krzepota, J.; Biernat, E.; Florkiewicz, B. The relationship between levels of physical activity and quality of life among students of the University of the Third Age. Cent. Eur. J. Public Health 2015, 23, 335-339.

44. Chai, W.; Nigg, C.; Pagano, I.; Motl, R.; Horwath, C.; Dishman, R. Associations of quality of life with physical activity, fruit and vegetable consumption, and physical inactivity in a free living, multiethnic population in Hawaii: A longitudinal study. Int. J. Behav. Nutr. Phys. Act. 2010, 7, 83. [CrossRef]

45. Hannan, J.; Brooten, D.; Youngblut, J.; Hildago, I.; Roche, R.; Seagrave, L. Physical activity and stress in adult Hispanics. J. Am. Assoc. Nurse Pract. 2015, 27, 79-86. [CrossRef]

46. Herman, K.; Hopman, W.; Craig, C. Sex differences in the association of youth body mass index to adult health-related quality of life: The physical activity longitudinal study. Can. J. Public Health 2011, 102, 42-46. [CrossRef]

(C) 2020 by the authors. Licensee MDPI, Basel, Switzerland. This article is an open access article distributed under the terms and conditions of the Creative Commons Attribution (CC BY) license (http://creativecommons.org/licenses/by/4.0/). 